\title{
Towards Citizen Science Communication How can citizen science enhance science communication?
}

Background

Science communication has shifted significantly in recent decades. From an early, widespread understanding that scientific findings were disseminated in a linear, closed pathway - from expert to layperson - there is now widespread acknowledgement of the need for more comprehensive and inclusive participation in science [cf. Massarani et al., 2017; Schäfer et al., 2015].

As a result of such progress, people's right to participate in scientific processes, and opportunities to do so, have expanded considerably. The idea of the 'active citizen' is now a central concept in the discourse on science and communication, and revolves around ideas such as exchange, reciprocity and inclusion of concrete and specific conditions of each situation [cf. Hecker et al., 2018; Weitze and Heckl, 2016; Schiele, 2008; Trench, 2006].

\section{Citizen Science}

Citizen science describes a range of practices that integrate people "who are not full-time professionals in the field of related science, with or without the participation of full-time researchers" [Pettibone et al., 2018: 6; see also Haklay et al., 2020; Franzen, 2016; Serrano et al., 2014] Citizen science is a transdisciplinary approach that responds to current requirements: Citizen science opens up research processes by involving citizens at different phases of scientific work.

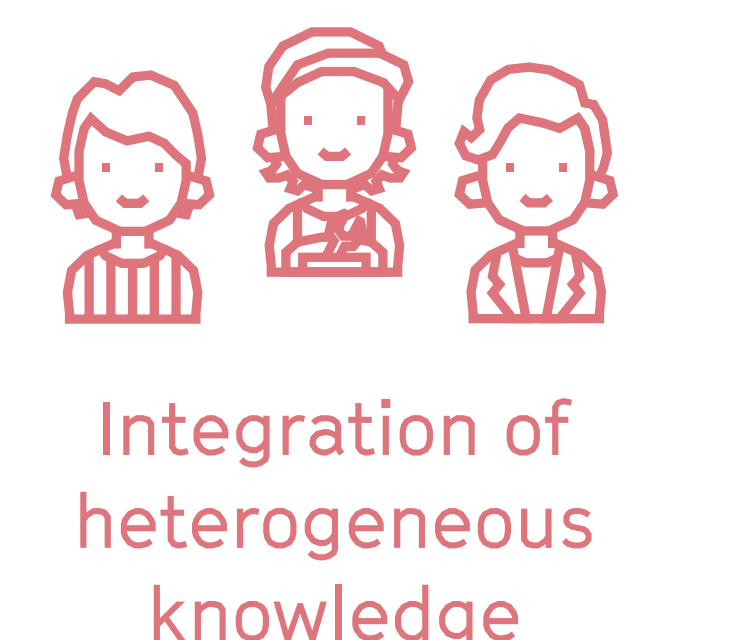

knowledge

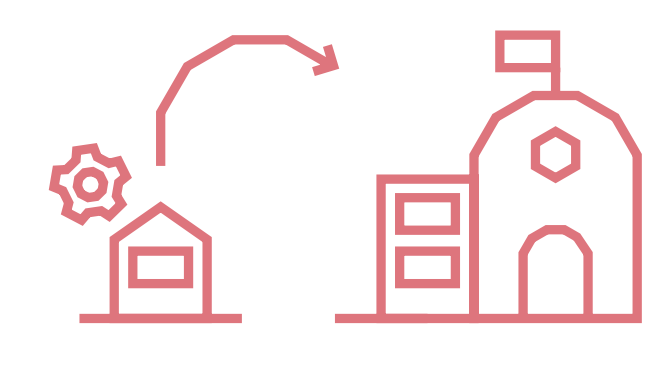

Taking everyday

nowledge as an

epistemic category

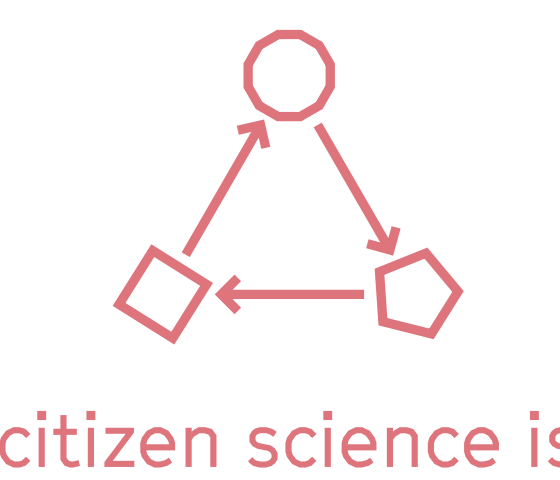

process-oriented

Communication in citizen science

is always Science Communication

Communication in Citizen Science is always science communication, and imposes specific conditions on science communication - by opening the "black box" [cf. Latour and Woolgar, 1979: 28] of knowledge production and establishes the requirement that communication be found for this purpose ((see Wagenknecht et al (2021), A question of dialogue? Reflections on how citizen science can enhance communication between science and society, in JCOM)
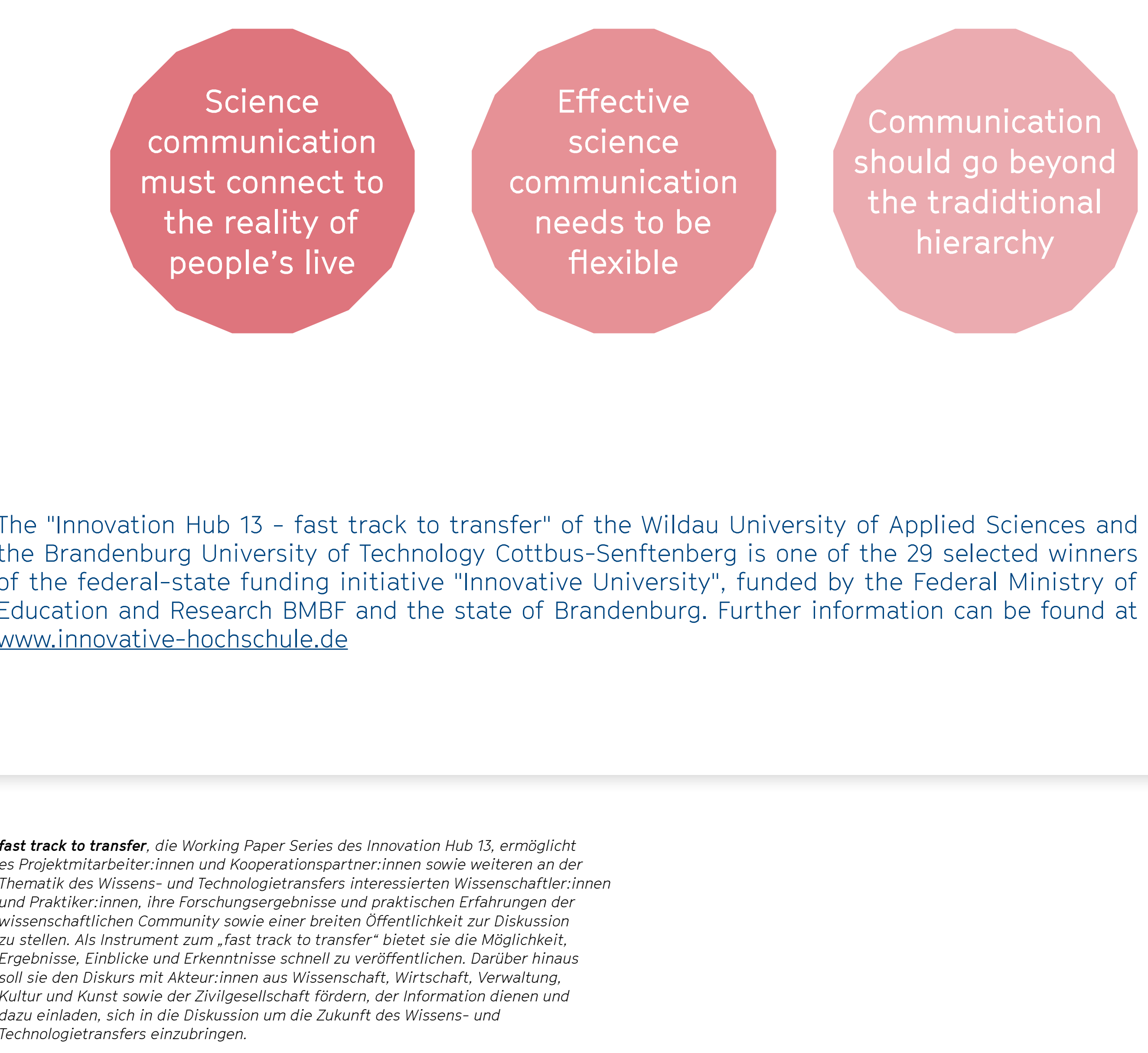

\section{forschen!}

Gemeinsam. In der Region.

The project outlines an argumentation of understanding citizen science as science communication. In the communication come into play, which establish with different intentions and approaches. In this communication.

Erklär uns deine Stadt! Erklär uns Luckenwalde!

The Citizen Science project "Explain your city to me" is thowledge and perspectives of the residents as the perceptions and knowledge about Luckenwalde. take around 30 minutes to answer, are answered by talk. The jointly developed narratives and exhibition.

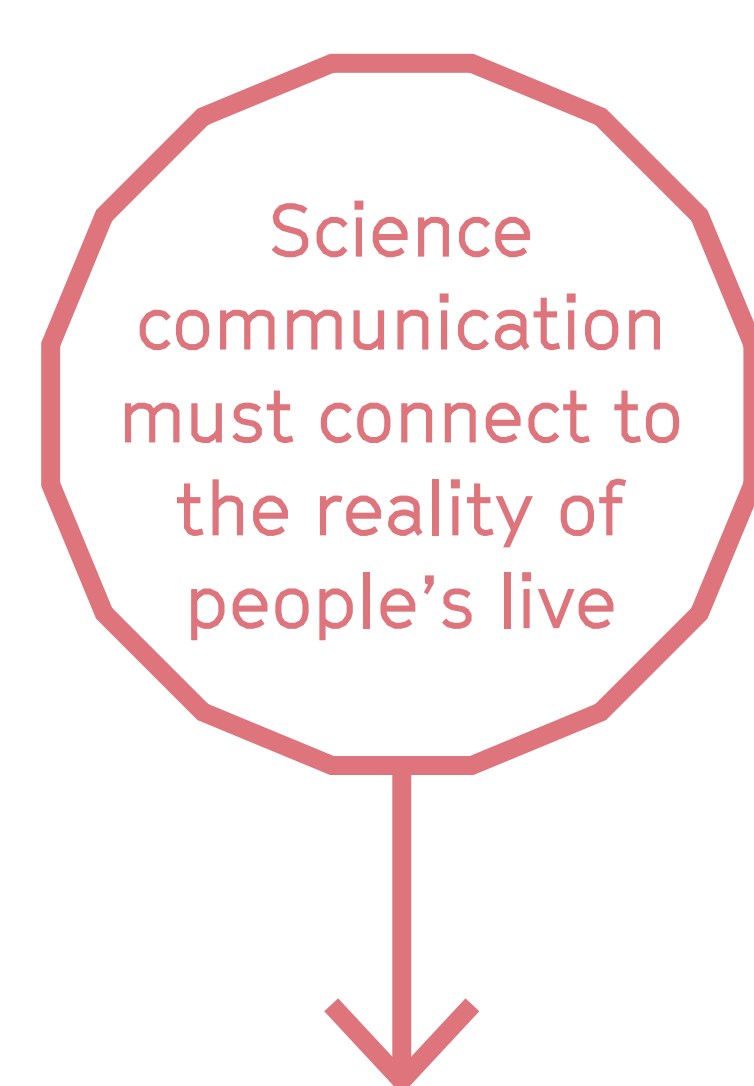

Participants are asked about everyday reality,
environment and everyday situations Sarah Klemisch MA Kamila Labuda 